\title{
Influence of bainite morphology on impact toughness of continuously cooled cementite-free bainitic steels
}

\author{
F.G. Caballero ${ }^{1}$, H. Roelofs ${ }^{2}$, St. Hasler ${ }^{2}$, C. Capdevila ${ }^{1}$, J. Chao ${ }^{1}$, J. Cornide $^{1}$, C. \\ Garcia-Mateo ${ }^{1}$ \\ ${ }^{1}$ Department of Physical Metallurgy, Spanish National Center for Metallurgical \\ Research (CENIM-CSIC), Avda Gregorio del Amo, 8; Madrid, E-28040, Spain, \\ ${ }^{2}$ R\&D, Swiss Steel AG, Emmenweidstr. 90, CH-6020 Emmenbrücke, Switzerland, \\ Corresponding Author: \\ F.G. Caballero \\ Spanish National Center for Metallurgical Research (CENIM-CSIC) \\ Av. Gregorio del Amo, 8 \\ 28040 MADRID \\ Spain \\ Tlf: +34915538900 (Ext 373) \\ Fax +3491534 7425 \\ E-mail: fgc@cenim.csic.es
}

\begin{abstract}
The influence of bainite morphology on the impact toughness behaviour of continuously cooled cementite-free low carbon bainitic steels has been examined. In these steels, bainitic microstructures formed mainly by lath-like upper bainite, consisting of thin and long parallel ferrite laths, were shown to exhibit higher impact toughness values than those with a granular bainite, consisting of equiaxed ferrite structure and discrete island of marteniste/austenite (M/A) constituent. Results suggest that the mechanism of brittle fracture of cementite-free bainitic steels involves nucleation of microcracks in M/A islands but is controlled by the bainite packet size.
\end{abstract}

Keywords: EBSD, electron microscopy, light microscopy, X-ray diffraction, bainite, steel

\section{Introduction}

The well-known difference in carbide distribution between bainite formed at high and low temperatures, viz., interlath and intralath, respectively, appears to exist in a majority of steels and makes the classical nomenclature of upper and lower bainite useful, both in describing the microstructural appearance and in classifying the overall reaction mechanism. In upper bainite, the carbides precipitate from carbon-enriched residual austenite. Upper bainitic ferrite itself is free from precipitates. The precipitation of carbides in upper bainite is a secondary process, not essential to the mechanism of formation of bainitic ferrite except where any precipitation from austenite will deplete its carbon content, thereby promoting further transformation. In contrast, there are many observations that reveal that lower bainitic cementite nucleates and grows within supersaturated ferrite in a process identical to the tempering of martensite [1]. The slower diffusion associated with the reduced transformation temperature provides an 
opportunity for some of the carbon to precipitate in the supersaturated bainitic ferrite. A fine dispersion of plate-like carbides is then found inside the ferrite plates, with a single crystallographic variant within a given ferrite plate, although it is possible to observe more than one variant of carbide precipitation in a lower bainite sub-unit [1,2]. In literature other categorization schemes for the description of bainite have been proposed [3-7]. These additional classifications can be useful in describing the form of the microstructure, but the mechanisms of all the bainitic transformations are the same among all the morphologies. Ohmori and co-workers [3,4] claimed that in view of crystallographic definition of bainite, the classification of bainite should be based on ferrite morphology but not cementite dispersion i.e. the shape of ferrite is lath-like or plate-like. They proposed a broader classification of bainitic-type microstructures for low-carbon and alloy carbon steels, where cementite is not associated with intermediatetemperature austenite transformation. Following Ohmori's description, the ferrite of upper bainite in low-carbon steels will always have a lath-like morphology, but bainite may be carbide-free (Type I), with austenite retained between laths, or has the cementite particles in the shapes of layers between ferrite laths (Type II) or has fine platelets lying parallel to a specific ferrite plane in the interior (Type III). As martensite, bainite would change its morphology from lath-like to plate-like increasing carbon content.

Bramfitt and Speer [5] proposed a new classification system encompassing both isothermally transformed and continuously cooled bainitic microstructures. Bainite morphologies are classified as B1, B2, or B3, depending on whether the lath of ferrite is associated with i) intralath precipitates, (ii) interlath particles/films, or (iii) discrete regions of retained austenite and/or secondary transformation product (e.g., martensite or pearlite), respectively. Krauss and Thompson [6] qualified the Bramfitt-Speer bainite classification system as the most compressive proposal to date for bainite morphologies, but they also showed that this system does not describe all of the ferritic microstructures observed in continuously cooled low-carbon steels. For instance, granular bainite, consisting of dispersed retained austenite or martensite/austenite (M/A) constituent with a granular or equiaxed morphology in a featureless matrix which may retain the prior austenite grain boundary structure, is incorporated into Bramfitt-Speer classification system by including a category of bainite consisting of lath-like ferrite with discreteisland constituent (B3). However, it is difficult to see how secondary phases can assume equiaxed morphologies in a matrix of lath-like ferrite.

More recently, S. Zajac et al. [7] provide a unified terminology, which may be applied for both low-carbon and high-carbon bainite. In this new classification, bainite is divided into three main groups depending on ferrite morphology and the type and distribution of second phases: i) Granular bainite with irregular ferrite; ii) Upper bainite with lath-like ferrite and the second phases on lath boundaries; and iii) Lower bainite, lath-like or plate-like, with cementite within the ferrite plates or laths. The microstructure of low carbon high strength steels, composed of bainitic ferrite with M/A constituent is called cementite-free bainite in the Ohmori et al. classification [4,5]. This bainite is, however, similar to the granular bainite at the micro-scale. The upper bainite which does not contain carbides but the M/A constituent is called degenerated upper bainite by Zajac et al. [7]. Lower bainite having cementite forming within the ferrite crystal is divided into two groups which have either lath morphology, typical for lowcarbon steels or plate morphology which is typical for lower bainite in steels with higher carbon levels.

It is important to remark that granular bainite microstructure under the optical and scanning electron microscopes is observed as granular-shaped coarse ferrite plates with islands of retained austenite and martensite. However, granular-shaped coarse ferrite 
plates do not really exist. In fact, they are sheaves of bainitic ferrite with very thin regions of austenite between the sub-units because of the low carbon concentration of the steels involved [8]. The definition of granular bainite given by Zajac et al. [7] is based on microstructural observations, including optical microscopy and scanning electron microscopy, which are not of sufficient resolution to reveal the fine structure within the granular bainite.

The precipitation of cementite during bainitic transformation can be suppressed in low carbon steel using controlled rolling followed by multi-stage cooling processes [4] and alloying the steel with silicon (>1\%), a well-known carbide inhibitor in steels [9]. The carbon that is rejected from the bainitic ferrite enriches the residual austenite, thereby stabilising (partially or totally) it down to ambient temperature. The resulting microstructure consists of bainitic ferrite and M/A constituent. In this paper we will refer to this microstructure as cementite-free bainite.

Silicon can avoid the precipitation of cementite between the plates of bainitic ferrite, but it is ineffective in retarding the precipitation of cementite from ferrite plates at lowtemperature condition [9]. Therefore, the formation of lower bainite is not inhibited in these steels. Following Zajac et al. classification [7], only granular bainite and degenerated upper bainite morphologies, can be considered as a cementite-free bainitic microstructure in these steels. These morphologies will be referred to as granular bainite and cementite-free lath-like upper bainite as Fig. 1 shows.

It is clear that the term bainite describes a variety of different complex microstructures that offer diverse combinations of strength and toughness. In industrial practice commercial bainitic steel grades with small variation on the diameter of the finished product, and thereby the cooling rate, may exhibit significant differences on toughness values that conventional microstructural characterisation as used for quality control is not able to explain. In this work, two commercial steels were sampled from the hot rolling mill and different continuously cooled bainitic microstructures were quantitatively analysed using scanning electron microscopy (SEM) and electron back scatter diffraction (EBSD) techniques to investigate the relationship between the morphology and impact toughness of bainite.

\section{Experimental Procedure}

Two commercial low carbon bainitic steels with different strength levels were chosen for microstructural investigations. The steels were conventionally hot rolled (wire rods with diameters ranging from 13 to $17 \mathrm{~mm}$ ) applying different cooling procedures after the last rolling pass at $\sim 1100^{\circ} \mathrm{C}$. The cooling rate between $800^{\circ} \mathrm{C}$ and $500^{\circ} \mathrm{C}$ was varied from 1.5 to $2.5^{\circ} \mathrm{C} / \mathrm{s}$. Before measuring tensile properties and impact strength the samples were tempered for one hour at $300^{\circ} \mathrm{C}$ to simulate industrial tempering of the bars in the bundles. Negligible change in the bainitic microstructure is expected after tempering for $1 \mathrm{~h}$ at $300^{\circ} \mathrm{C}$ [10]. Steel 1 is a C-Mn-Si-Cr steel [11] with a tensile strength level of $\sim 1200 \mathrm{MPa}$, whereas Steel 2 is a microalloyed C-Mn-B type of steel $[12,13]$ with a much lower tensile strength level of $\sim 800 \mathrm{MPa}$. The chemical composition of the studied steels is shown in Table 1. Steel 2 with the lower impact strength after hot rolling was chosen for further tests simulating more elevated cooling rates. For this purpose 10x10x80 mm samples were re-austenised $\left(910^{\circ} \mathrm{C}\right)$ in a Gleeble machine. Samples were cooled at fixed cooling rates of 3 and $9{ }^{\circ} \mathrm{C} / \mathrm{s}$, respectively. The influence of the prior austenite grain size on the morphology of bainite was also investigated. For this purpose, austenitisation at $1200{ }^{\circ} \mathrm{C}$ and subsequent cooling at 9 
${ }^{\circ} \mathrm{C} / \mathrm{s}$ was performed in one of the studied samples. Table 2 lists the investigated steel samples and the corresponding process conditions.

Tensile specimens with a section of $8 \mathrm{~mm}$ diameter and a gauge length of $40 \mathrm{~mm}$ (B8x40) were tested at room temperature according to standard DIN EN ISO 6892-1 :2009 (method B: stress rate controlled). Impact energies were measured on Charpy Vnotched $\left(10 \times 10 \mathrm{~mm}^{2}\right)$ samples at room temperatures using a $300 \mathrm{~J}$ Charpy testing machine. Only in case of the $13 \mathrm{~mm}$ wire rod smaller samples of $9 \times 9 \mathrm{~mm}^{2}$ were taken. Specimens were tested in accordance with standard DIN EN 10045-1: 1990. The impact strength values in $\mathrm{J} / \mathrm{cm}^{2}$ were used for comparison. Fractography was carried on the Charpy impact toughness specimens using a Hitachi S 2100 operating at $15 \mathrm{kV}$. The size of facets in the cleavage region has been estimated by standard quantitative metallographic method on fractographs at magnification of x500-x1000.

Specimens were ground and polished using standardised techniques for metallographic examination. A 2 pct Nital etching solution was used to reveal the microstructure by LOM. For more detailed microstructural characterizations, SEM was carried out on a Jeol JSM-6500F field emission scanning electron microscope operating at $7 \mathrm{kV}$. The volume fraction and size of $\mathrm{M} / \mathrm{A}$ constituent were estimated by standard quantitative metallographic method on SEM micrographs at a magnification of x1500-x2000.

Quantitative X-ray analysis was applied to determine the fraction of retained austenite. After grinding and final polishing using $1 \mu \mathrm{m}$ diamond paste, the samples were etched to obtain an undeformed surface. They were then step-scanned in a SIEMENS D 5000

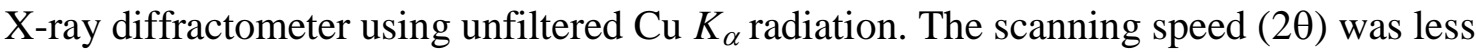
than 0.3 degree $/ \mathrm{min}$. The machine was operated at $40 \mathrm{kV}$ and $30 \mathrm{~mA}$. The retained austenite content was calculated from the integrated intensities of (200), (220) and (311) austenite peaks, and those of (002), (112) and (022) planes of ferrite. Using three peaks from each phase avoids biasing the results due to any crystallographic texture in the samples. The carbon concentration in the austenite was estimated by using the lattice parameter of the retained austenite [14].

EBSD patterns were collected at various locations on sections carefully polished with $50 \mathrm{~nm}$ colloidal silica suspension in the final stage of metallography preparation. The EBSD patterns were generated at an acceleration voltage of $20 \mathrm{kV}$ and collected using a CHANNEL 5 detector of HKL Technology. The indexation of the Kikuchi lines and the determination of the orientations were done with software also developed by HKL Technology. The results were represented by means of an inverse pole figure maps, which give the orientation of a macroscopic direction with respect to a specific crystal direction. The crystallographic packet size $\left(\mathrm{d}_{\mathrm{B}}\right)$ was determined as the mean distance between high-angle boundaries $\left(>15^{\circ}\right)$ that a cleavage crack would find during its propagation. It has been measured from the misorientation maps. For each scanned zone, two lines were traced from the corners to the opposite corners of the area, and a third line was traced parallel to the minor side of the rectangular area in such a way that the three lines intersect in one point. For each sample, three rectangular zones including about 400 bainite packets were scanned using EBSD technique.

\section{Results and Discussion}

Figure 2 illustrates SEM micrographs of all the studied samples. Quantitative experimental data of these microstructures are presented in Table 3. All samples have a microstructure consisting of mainly cementite-free bainitic ferrite and M/A constituent. 
Two different morphologies of bainite have been identified by SEM depending on the cooling rate and the prior austenite grain size in the samples: cementite-free lath-like upper bainite, consisting of thin and long parallel ferrite laths, and granular bainite, revealed as equiaxed ferrite structure and discrete island of $\mathrm{M} / \mathrm{A}$ constituent.

The SEM micrographs clearly show the differences in morphology of bainite among the investigated samples. Steel 1-2.5 sample shows thin, long and slender well defined laths (see Fig. 2.a) typical of high strength high toughness bainitic steels, meanwhile the nature of bainite in Steel 1-2 sample seems to be coarser (See Fig. 2.b), leading to lower strength and toughness values as shown in Table 4. Moreover, bainitic microstructure in Steel 1-2 sample exhibits a distribution of M/A constituent in the bainitic ferrite matrix as equiaxed M/A grains, instead of very thin films between subunits within a given sheaf of bainite.

On the other hand, increasing prior austenite grain size and decreasing cooling rate in Steel 2 enhances the formation of granular bainite at the expense of lath-like upper bainite as Figs. 2.c-2.f suggest. It is also observed that the lower the cooling rate is, the coarser the M/A grains inside granular bainite are. Table 5 summarises the different in morphologies of bainite observed in all the studied samples.

Granular bainite is supposed to occur only in steels which have been cooled continuously. It can not be produced by isothermal transformation [15]. The extent of transformation to granular bainite is found to depend on the undercooling below the bainite start temperature [16]. This is a reflection of the fact that the microstructure, like lath-like bainite, exhibits an incomplete reaction phenomenon [17]. The evidence indicates that granular bainite is not different from lath-like bainite in its transformation mechanism. The differences between both morphologies of bainite are mainly a consequence of slow continuous cooling transformation that permits extensive transformation to bainite during gradual cooling to room temperature [17].

A characteristic feature of granular bainite is the lack of carbides in the microstructure. The carbon that is partitioned from the bainitic ferrite stabilises the residual austenite, so that the final microstructure contains both retained austenite and some high carbon martensite. Consistent with observations on lath-like upper bainite, there is not redistribution of substitutional solutes during the formation of granular bainite $[18,19]$

Impact toughness values achieved in cementite-free bainitic microstructures are generally attributed to the amount of martensite, $\mathrm{V}_{\mathrm{M}}$, [20-22]. In principle, the presence of a very hard phase, such as martensite, in a bainitic microstructure, would deteriorate toughness as it has been extensively reported [20-22]. However, Chatterjee and Bhadeshia [23] proposed and showed experimentally that the load transfer into the hard martensite becomes similarly difficult as the scale of the martensite decreases in a relatively soft matrix. In other words, the martensite will not crack easily if its size is reduced below some critical value typically around $10 \mu \mathrm{m}$. Naturally, work hardening comes into this scenario so that sufficient load should eventually be transferred into the martensite to cause fracture. However, the stage at which this occurs ought to be delayed when the martensite is fine.

Results in Table 3 suggest that the amount of martensite in the microstructure does not fully explain the toughness behaviour of the studied samples (Table 4). For instance, Steel 2-3 sample with a martensite content of $0.05 \pm 0.03$ in the bainitic microstructure reaches lower impact toughness value $\left(121 \mathrm{~J} / \mathrm{cm}^{2}\right)$ than Steel 2-9 sample $\left(208 \mathrm{~J} / \mathrm{cm}^{2}\right)$ with a martensite content of $0.12 \pm 0.03$. The size distribution of the M/A constituent 
(films and grains) was also quantitative determined in the studied samples. Table 5 lists mean values of the size of the M/A films present in lath-like upper bainite and equiaxed M/A grains in granular bainite. The films of M/A constituents present in lath like upper bainite are remarkable small $(\sim 0.13 \mu \mathrm{m})$ in comparison to the $\mathrm{M} / \mathrm{A}$ grains in granular bainite $(\sim 1.5 \mu \mathrm{m})$. In case of a granular bainitic microstructure differences in M/A grain size might affect impact toughness. Figure 3 illustrates the size distribution of equiaxed $\mathrm{M} / \mathrm{A}$ grains in microstructures with granular bainite morphology in the different samples. Comparing these data with the impact strength values in Table 4 there is some indication that the presence of coarse equiaxed martensite islands with a diameter of 4-6 $\mu \mathrm{m}$ might cause brittle behaviour in these bainitic microstructures.

In addition to the coarse M/A grains, fracture may be controlled by microstructural features such as bainite packet [24-26]. Bainite is a microstructure made up of packets of parallel plates in the so-called morphological packet. The good toughness of this microstructure is related to the high density of the high-angle boundaries that these microstructures usually present [27]. This kind of boundaries acts as obstacles to cleavage propagation, forcing the cleavage crack to change the microscopic plane of propagation in order to accommodate the new local crystallography [28]. Low-angle boundaries are not effective obstacles and, consequently, seem to have no influence on the toughness of steels. For this reason, from the point of view of the fracture micromechanism, it is more convenient to use the concept of a crystallographic packet [27], defined as the continuous set of ferrite plates with a crystallographic misorientation lower than a certain angle $\left(15^{\circ}\right.$ here $)$, instead of the previously defined concept of a morphological packet.

Figure 4 illustrates the differences on the type of grain boundaries (low or high angles) and grain boundaries misorientation between lath-like upper bainite (Fig. 4.a) and granular bainite (Fig. 4.b and 4.c). It is clear from the misorientation map that the effective crystallographic packet i.e. the continuous set of ferrite plates with a crystallographic misorientation lower than a certain angle in lath-like upper bainite is finer than in granular bainite. Table 6 lists the crystallographic packet size, $d_{B}$, determined from misorientation maps (See three examples in Fig. 4) as the mean distance between high-angle boundaries $\left(>15^{\circ}\right)$ that a cleavage crack would find during its propagation. Results confirm that granular bainite exhibit coarser bainite crystallographic packets $(\sim 7-15 \mu \mathrm{m})$ when compare with lath-like upper bainite $(\sim 4-7$ $\mu \mathrm{m})$.

Subsuming these results, a combination of M/A size distribution and bainite packet size give an explanation for the found differences in Charpy impact strength. Granular bainite contains discrete island of $\mathrm{M} / \mathrm{A}$ constituent and forming relatively large effective grain size. These conditions limit the reachable level of impact strength. By contrast, lath-like upper bainite contains small M/A films and the bainite morphology consists of small effective grains with a high interior dislocation density.

The SEM micrographs of the fracture surface of Steel 1-2.5 and Steel1-2 impact specimens tested at room temperature are shown in Figs. 5 and 6, respectively. Three regions are visible below the stretched zone: shear fracture $(\mathrm{SF})$ region measured to be $70 \%$ in Steel 1-2.5 and 10\% in Steel 1-2; microvoid coalescence (MVC) region and cleavage (C) region. Although it was possible to identify fracture initiation site by tracing river lines to an origin on low magnification micrographs (Figs. 5 and 6), the initiation site itself was usually featureless. The identification of the cracks nucleation sites in these microstructures is currently under investigation, but it is believed that hard M/A grains are most susceptible for microcracks nucleation [22,29]. Ritchie et al. [30] 
provided indirect evidence that hard particles other than cementite can initiate cracks in bainitic steels.

The size of transgranular facets measured on SEM micrographs (See an example in Fig. 5.c) of the cleavage region of all the tested bainitic samples is listed in Table 6. The increase on the facet size detected on microstructures with granular bainite morphology must be closely related to the increase on the bainite packet size, $d_{B}$, measured by EBSD analysis. In general, the measured facet size has been found larger than the corresponding bainite packet size, except for the sample Steel 2-1200-9 where both values are very similar. The $d_{B}$ value is known to be related to the unit crack path or region in which the crack propagates almost in a straight line and corresponds to the distance between two neighbouring high-angle boundaries [24,31]. Morris et al [32] clearly illustrated that relationship in as-quenched a $9 \mathrm{Ni}$ steel using profile $\mathrm{SEM}$ fractographs of cleavage fracture. The steel is cleaved along $\{100\}$ planes that cross many laths within packet, meanwhile the crack branches at packet boundaries where the orientation of the $\{100\}$ planes changes.

Therefore, the brittle fracture of both continuously cooled cementite-free low carbon bainitic steels is governed by the extension of fast microcracks across low angle bainitic ferrite boundaries. Hard brittle phases such as M/A grains have an essential, because they permit the crack nucleus to form. The brittle fracture stress will then depend of two quantities: i) the size of the microcrack which corresponds with the M/A grain dimensions; and ii) the resistance to growth that the microcrack experiences when it attempts to cross the boundary. The microstructural feature whose boundaries resist microcrack extension in the studied steels has been found to be the bainite packets.

\section{Conclusions}

Microstructural characterisation and impact toughness evaluation of different continuously cooled cementite-free low carbon bainitic steels have demonstrated that bainitic microstructures formed mainly by lath-like upper bainite, consisting of thin and long parallel ferrite laths, exhibits higher impact toughness values than those with a granular bainite morphology revealed by the SEM as equiaxed ferrite structure and discrete island of M/A constituent. Granular bainite shows evidence of low resistance to crack propagation during cleavage fracture because of its larger crystallographic packet size. Moreover, the stress concentration associated with coarse M/A grains is considered as a possible factor contributing to the premature crack nucleation.

\section{Acknowledgments}

J. Cornide acknowledges the Spanish Ministry of Science and Innovation for financial support in the form of a PhD research grant (FPI grant under the Project MAT200763873).

\section{References}

[1] H. K. D. H. Bhadeshia: Acta Metall., 1980, 28, 1103-1114.

[2] L. C. Chang: Mater. Sci. Eng. A, 2004, 368A. 175-182.

[3] Y. Ohmori, H. Ohtani and T. Kunitake, Trans. Iron Steel Inst. Jpn., 1971, 11, 250259.

[4] H. Ohtani, S. Okaguchi, Y. Fujishiro and Y. Ohmori: Metall. Trans. A, 1990, 21, 877-888. 
[5] B. L. Bramfitt and J. G. Speer: Metall. Trans. A, 1990, 21, 817-829.

[6] G. Krauss and S. W. Thomson: ISIJ Inter., 1995, 35, 937-945.

[7] S. Zajac, J. Komenda, P. Morris, P. Dierickx, S. Matera and F. Penalba Diaz: 'Quantitative Structure-Property Relationship for Complex Bainitic Microstructures', European Commission, Technical Steel Research, Report EUR 21245EN, Luxembourg, 2005.

[8] B. Josefsson and H.O. Andren, in Proc. of the $35^{\text {th }}$ Int. Field Emission Symp., Oak Rdige, Tennessee, USA, 1988, 18-22.

[9] E. Kozeschnik and H. K. D. H. Bhadeshia: Mater. Sci. Technol., 2008, 24, 343347.

[10] F. G. Caballero, H. K. D. H. Bhadeshia, K. J. A. Mawella, D. G. Jones and P. Brown: Mater. Sci. Technol., 2001, 17, 517-522.

[11] H. Roelofs, U. Urlau, M. Lembke and G. Olschewski: in 'Future Trends in Steel Development, Processing Technologies and Applications: SCT2008', (ed. B.

Fuchsbauer and H.-J. Wieland), 205- 211; 2008, Düsseldorf, Verlag Stahleisen GmbH. [12] S. Waengler: 'Ultra Low Carbon Bainitic Steels for Cold Heading Applications', B 344; 2008, Freiberger Forschungshefte.

[13] R. Kuziak, S. Zajac, R. Kawalla, S. Waengler, K. Stercken, J. Noack, M. Safi, R. Jakubczak, R. Urlau, S. Hasler and L. Chabbi: 'Cold Heading Quality Low-Carbon Ultra-High-Strength Bainitic Steels', Research Fund for Coal and Steel, European Commission, Technical Steel Research, Report EUR 24191, Luxembourg, 2010.

[14] D. J. Dyson and B. Holmes: J. Iron Steel Inst., 1970, 208, 469-474.

[15] L. J. Habraken: Rev. Met., 1956, 53, 930-944.

[16] L. J. Habraken and M. Economopolus: 'Transformation and Hardenability in Steels', 1967, Ann Arbor, Michigan, Climax Molybdenum.

[17] H. K. D. H. Bhadeshia: 'Bainite in steels', 2nd edn, 2001, London, IoM Communications.

[18] T. A. L. Azevedo and E. Galvao-da-Silva: Scripta Metall., 1978, 12, 113-117.

[19] F. G. Caballero, M. K. Miller, S. S. Babu and C. Garcia-Mateo: Acta Mater., 2007, 55, 381-390.

[20] H. K. D. H. Bhadeshia and D. V. Edmonds: Met. Sci., 1983, 17, 411-419.

[21] H. K. D. H. Bhadeshia and D. V. Edmonds: Met. Sci., 1983, 17. 420-425.

[22] F. G. Caballero, J. Chao, J. Cornide, C. García-Mateo, M.J. Santofimia and C. Capdevila: Mater. Sci. Eng. A, 2009, 52, 587-95.

[23] S. Chatterjee and H. K. D. H. Bhadeshia: Mater. Sci. Technol., 2006, 22, 645-649.

[24] P. Brozzo, G. Buzzichelli, A. Mascanzoni and M. Mirabile: Met. Sci., 1977, 11, 123-129.

[25] A. Kamada, N. Koshizuka and T. Funakoshi: Trans. Iron and Steel Inst. of Japan, 1976, 16. 407.

[26] H. Kotilainen, K. Torronen and P. Neonen: in 'Advances in Fracture Research', (ed. D. Francois), Vol. 2, 723; 1982, Oxford, Pergamon Press.

[27] A. F. Gourgues, H. M. Flower and T. C. Lindley: Mater. Sci. Technol., 2000, 16, 26-40.

[28] J. M. Rodríguez-Ibabe: Mater. Sci. Forum, 1998, 284-286, 51-62.

[29] D. Das and P. P. Chattopadhyay: J. Mater. Sci., 2009, 44, 2957-2965.

[30] R. O. Ritchie, W. L. Server and R. A. Wullaert: Metall. Trans. A, 1979, 10, 15571570.

[31] Y. Ohmori, H. Ohtani and T. Kunitake: Met. Sci., 1974, 8, 357-366.

[32] J. W. Morris, C. S. Lee and Z. Guo: ISIJ Int., 2003, 43, 410-419. 



\section{Figure Captions:}

Figure 1.- Morphological classification used in this work based on Zajac et al.'s categorization scheme [7] and microstructural observations, including optical microscopy and scanning electron microscopy, which are not of sufficient resolution to reveal the fine structure within the granular bainite.

Figure 2.- Scanning electron micrographs of the continuously cooled bainitic samples: (a) Steel 1-2.5; (b) Steel 1-2; (c) Steel 2-9; (d) Steel 2-3; (e) Steel 2-1.5; and (f) Steel 21200-9. LLUB is lath-like upper bainite; GB is granular bainite.

Figure 3.- Size distribution of the equiaxed M/A grains present in granular bainite of the continuously cooled bainitic samples: (a) Steel 1-2; (b) Steel 2-3; (c) Steel 2-1.5; and (d) Steel 2-1200-9.

Figure 4.- Orientation imaging map, misorientation map (tolerance angle of $15 \mathrm{deg}$ ) and corresponding misorientation frequency graph of (a) lath-like upper bainite in Steel 1-9 sample and granular bainite in: (b) Steel 2-3 sample and (c) Steel 2-1.5 sample.

Figure 5.- Fractographs of Steel 1-2.5 impact specimen at room temperature. SZ is stretched zone; SF is shear fracture, MVC is microvoid coalescence; $\mathrm{C}$ is cleavage.

Figure 6.- Fractographs of Steel 1-2 impact specimen at room temperature. SZ is stretched zone; SF is shear fracture, MVC is microvoid coalescence; $\mathrm{C}$ is cleavage. Arrows identify fracture initiation site. 
Table 1.- Chemical composition of the studied steels, (wt-\%).

\begin{tabular}{llllllllllll}
\hline Steel & $\mathbf{C}$ & $\mathbf{S i}$ & $\mathbf{M n}$ & $\mathbf{N i}$ & $\mathbf{C r}$ & $\mathbf{M o}$ & $\mathbf{V}$ & $\mathbf{T i}$ & $\mathbf{B}$ & $\mathbf{N}$ & $\mathbf{S}$ \\
\hline Steel 1 & 0.15 & 1.19 & 1.50 & 0.08 & 1.19 & 0.311 & - & - & - & $76 \mathrm{ppm}$ & 0.003 \\
\hline Steel 2 & 0.07 & 0.21 & 1.86 & 0.10 & 0.11 & 0.024 & 0.04 & 0.08 & $15 \mathrm{ppm}$ & $99 \mathrm{ppm}$ & 0.007 \\
\hline
\end{tabular}


Table 2.- Cooling rate used during hot rolling simulation of the studied samples

\begin{tabular}{lll}
\hline Sample & Treatment & Cooling Rate \\
\hline Steel 1-2.5 & Hot rolling and tempering at $300^{\circ} \mathrm{C}$ for $1 \mathrm{~h}$ & $2.5^{\circ} \mathrm{C} / \mathrm{s}$ \\
Steel 1-2 & Hot rolling and tempering at $300^{\circ} \mathrm{C}$ for $1 \mathrm{~h}$ & $2{ }^{\circ} \mathrm{C} / \mathrm{s}$ \\
\hline Steel 2-9 & Gleeble Simulation $/ 910^{\circ} \mathrm{C}$ & $9^{\circ} \mathrm{C} / \mathrm{s}$ \\
Steel 2-3 & Gleeble Simulation $/ 910^{\circ} \mathrm{C}$ & $3{ }^{\circ} \mathrm{C} / \mathrm{s}$ \\
Steel 2-1.5 & Hot rolling and tempering at $300^{\circ} \mathrm{C}$ for $1 \mathrm{~h}$ & $1.5^{\circ} \mathrm{C} / \mathrm{s}$ \\
\hline Steel 2-1200-9 & Gleeble Simulation $/ 1200^{\circ} \mathrm{C}$ & $9^{\circ} \mathrm{C} / \mathrm{s}$ \\
\hline
\end{tabular}


Table 3.- Quantitative data on microstructure and hardness.

\begin{tabular}{llllll}
\hline Sample / Heat Treatment & $V_{\boldsymbol{B}}$ & $\boldsymbol{V}_{\boldsymbol{M}}$ & $\boldsymbol{V}_{\boldsymbol{\gamma}}$ & $\boldsymbol{x}_{\boldsymbol{p}}$ wt- $\%$ & $\begin{array}{l}\text { Hardness, } \\
\text { HV30 }\end{array}$ \\
\hline Steel 1-2.5 & $0.84 \pm 0.03$ & $0.10 \pm 0.02$ & $0.06 \pm 0.01$ & $0.97 \pm 0.03$ & $394 \pm 4$ \\
Steel 1-2 & $0.82 \pm 0.03$ & $0.12 \pm 0.02$ & $0.06 \pm 0.01$ & $0.88 \pm 0.03$ & $364 \pm 3$ \\
\hline Steel 2-9 & $0.87 \pm 0.04$ & $0.12 \pm 0.03$ & $0.01 * \pm 0.01$ & $0.51 \dagger \pm 0.03$ & $302 \pm 14$ \\
Steel 2-3 & $0.93 \pm 0.04$ & $0.05 \pm 0.03$ & $0.02 * \pm 0.01$ & $0.48 \dagger \pm 0.03$ & $254 \pm 10$ \\
Steel 2-1.5 & $0.90 \pm 0.03$ & $0.08 \pm 0.02$ & $0.02 * \pm 0.01$ & $0.75 \dagger \pm 0.03$ & $257 \pm 9$ \\
\hline Steel 2-1200-9 & $0.89 \pm 0.04$ & $0.09 \pm 0.03$ & $0.02 * \pm 0.01$ & $0.48 \dagger \pm 0.03$ & $247 \pm 5$ \\
\hline
\end{tabular}

$V_{B}$ is the volume fraction of bainitic ferrite; $V_{M}$ is the volume fraction of martensite; $V_{\gamma}$ is the volume fraction of retained austenite; and $x_{\gamma}$ is the carbon content in austenite. Hardness values are averaged over 10 tests. $†$ Unreliable austenite lattice parameter measurements due to the low volume fraction of austenite detected in the microstructure $(*)$. 
Table 4.- Tensile properties and Charpy impact test results at room temperature

\begin{tabular}{|c|c|c|c|}
\hline Sample & $\mathbf{R}_{\mathrm{m}}, \mathbf{M P a}$ & $\mathbf{A}_{5}, \%$ & ISO-V, J/cm ${ }^{2}$ \\
\hline Steel 1-2.5 & $1191 / 1212$ & $14.6 / 14.6$ & $178 *$ \\
\hline Steel 1-2 & $1152 / 1159$ & $14.6 / 15.3$ & $75^{*}$ \\
\hline Steel 2-9 & --- & --- & $208^{*}$ \\
\hline Steel 2-3 & --- & --- & $121 *$ \\
\hline Steel 2-1.5 & 740 & 20 & $39 *$ \\
\hline Steel 2-1200-9 & --- & --- & $68^{*}$ \\
\hline
\end{tabular}

*Measured value of investigated sample. 
Table 5.- Quantitative data on the M/A grain size distribution

\begin{tabular}{|c|c|c|c|}
\hline Sample & Morphology of Bainite & $\begin{array}{l}\text { M/A Grain Size, } \mu \mathrm{m} \\
\text { (Shape of } M / A)\end{array}$ & $\begin{array}{l}\text { Maximum M/A } \\
\text { Grain Size, } \mu \mathrm{m}\end{array}$ \\
\hline Steel 1-2.5 & Mainly LLUB & $\begin{array}{l}0.13 \pm 0.04 \\
\text { (Thin Films in LLUB) }\end{array}$ & 0.18 \\
\hline Steel 1-2 & Mixture of GB and LLUB & $\begin{array}{l}1.29 \pm 0.64 \\
\text { (Equiaxed Grains in GB) }\end{array}$ & 4.54 \\
\hline Steel 2-9 & Mainly LLUB. & $\begin{array}{l}0.12 \pm 0.03 \\
\text { (Thin Films in LLUB) }\end{array}$ & 0.18 \\
\hline Steel 2-3 & Mainly GB & $\begin{array}{l}1.30 \pm 0.89 \\
\text { (Equiaxed Grains in GB) }\end{array}$ & 3.61 \\
\hline Steel 2-1.5 & Mainly GB & $\begin{array}{l}1.73 \pm 0.84 \\
\text { (Equiaxed Grains in GB) }\end{array}$ & 5.61 \\
\hline Steel 2-1200-9 & Mainly GB & $\begin{array}{l}1.40 \pm 0.58 \\
\text { (Equiaxed Grains in GB) }\end{array}$ & 3.97 \\
\hline
\end{tabular}

LLUB is lath-like upper bainite; GB is granular bainite. 
Table 6.- Quantitative data on the bainitic ferrite crystallographic packet size, $d_{B}$, and the size of facets in the cleavage region of impact specimens

\begin{tabular}{llll}
\hline Sample & Morphology of Bainite & $\mathbf{d}_{\mathbf{B}}, \boldsymbol{\mu \mathbf { m }}$ & $\begin{array}{l}\text { Size of Facets, } \\
\boldsymbol{\mu m}\end{array}$ \\
\hline Steel 1-2.5 & Mainly LLUB & $4.3 \pm 0.5$ & $9 \pm 1$ \\
Steel 1-2 & Mixture of GB and LLUB & $6.3 \pm 0.3$ & $13 \pm 6$ \\
\hline Steel 2-9 & Mainly LLUB. & $7.0 \pm 1.7$ & $13 \pm 6$ \\
Steel 2-3 & Mainly GB & $7.3 \pm 0.8$ & $11 \pm 4$ \\
Steel 2-1.5 & Mainly GB & $13.8 \pm 2.0$ & $28 \pm 5$ \\
\hline Steel 2-1200-9 & Mainly GB & $15.2 \pm 2.2$ & $13 \pm 5$ \\
\hline
\end{tabular}

LLUB is lath-like upper bainite; GB is granular bainite. 


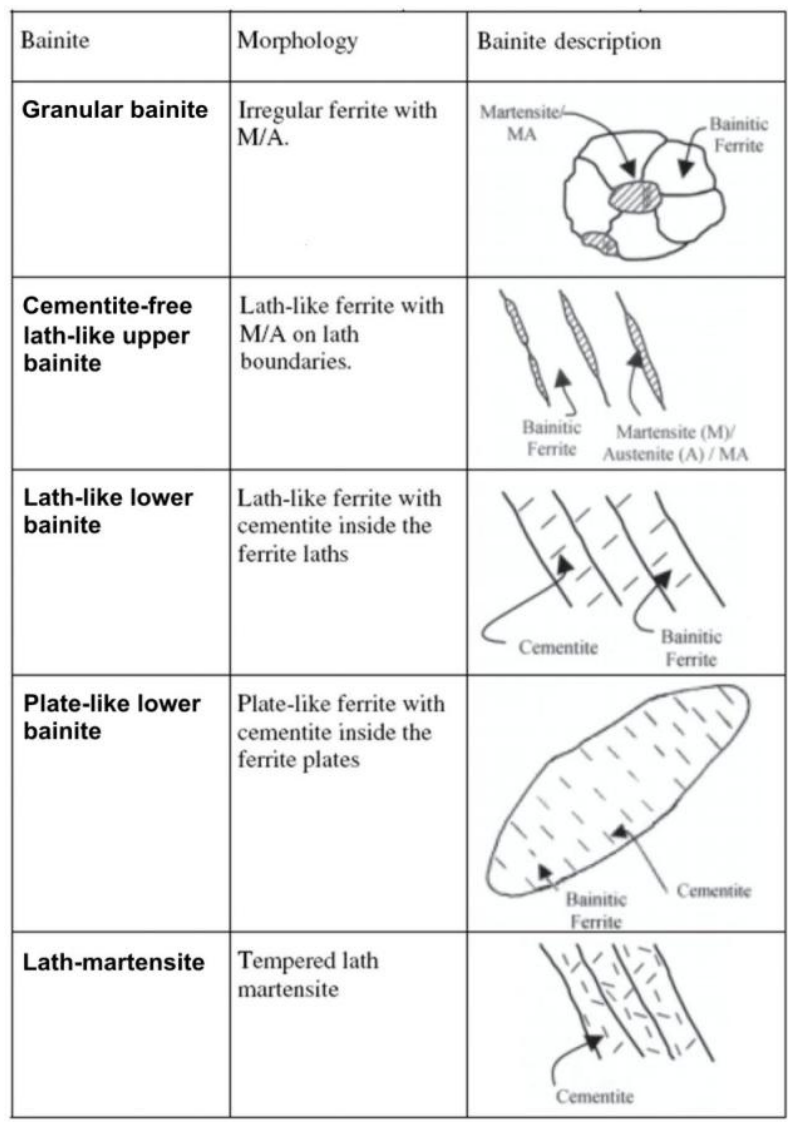

Figure 1.- Morphological classification used in this work based on Zajac et al.'s categorization scheme [7] and microstructural observations, including optical microscopy and scanning electron microscopy, which are not of sufficient resolution to reveal the fine structure within the granular bainite. 


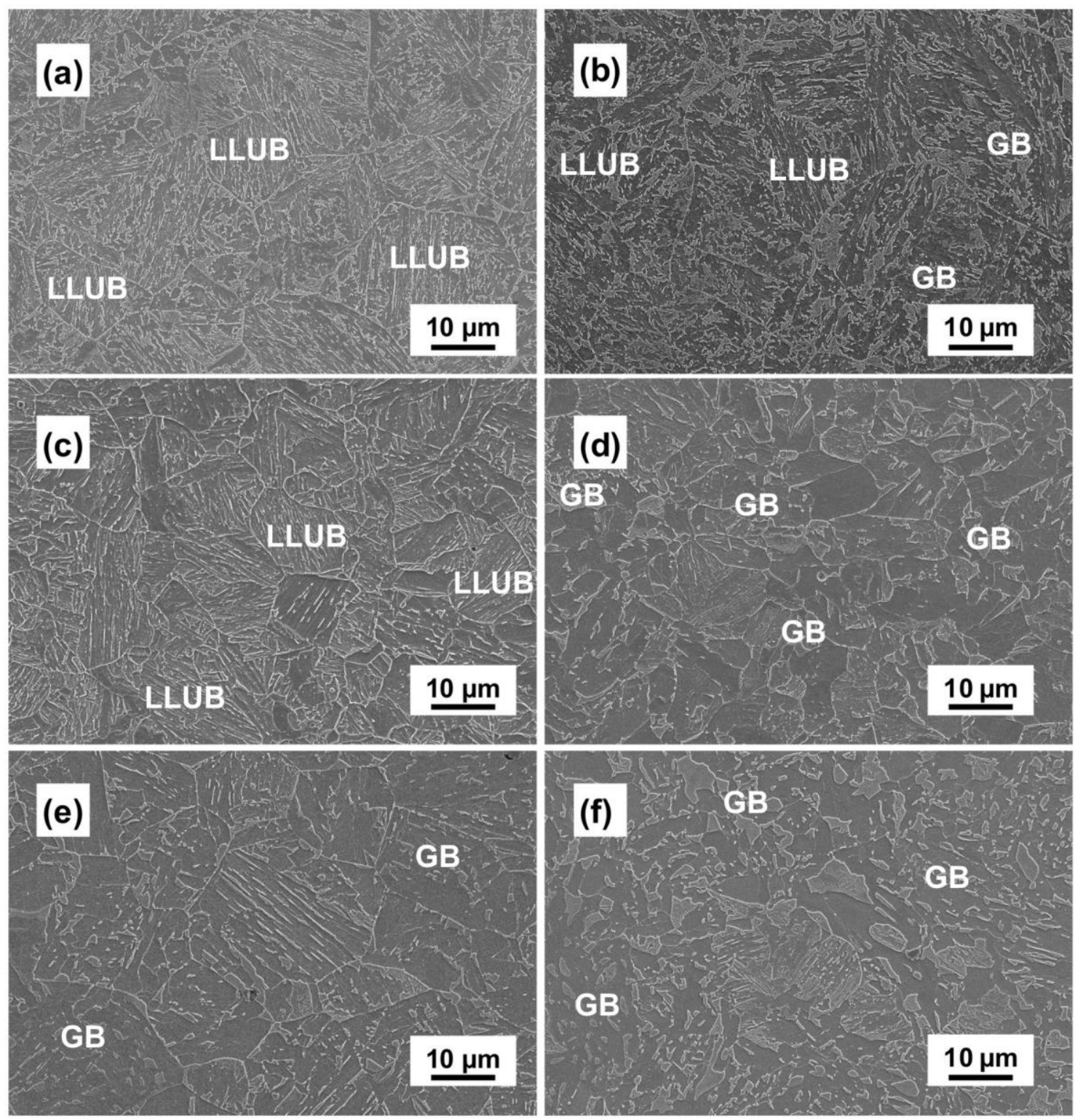

Figure 2.- Scanning electron micrographs of the continuously cooled bainitic samples: (a) Steel 1-2.5; (b) Steel 1-2; (c) Steel 2-9; (d) Steel 2-3; (e) Steel 2-1.5; and (f) Steel 21200-9. LLUB is lath-like upper bainite; GB is granular bainite. 

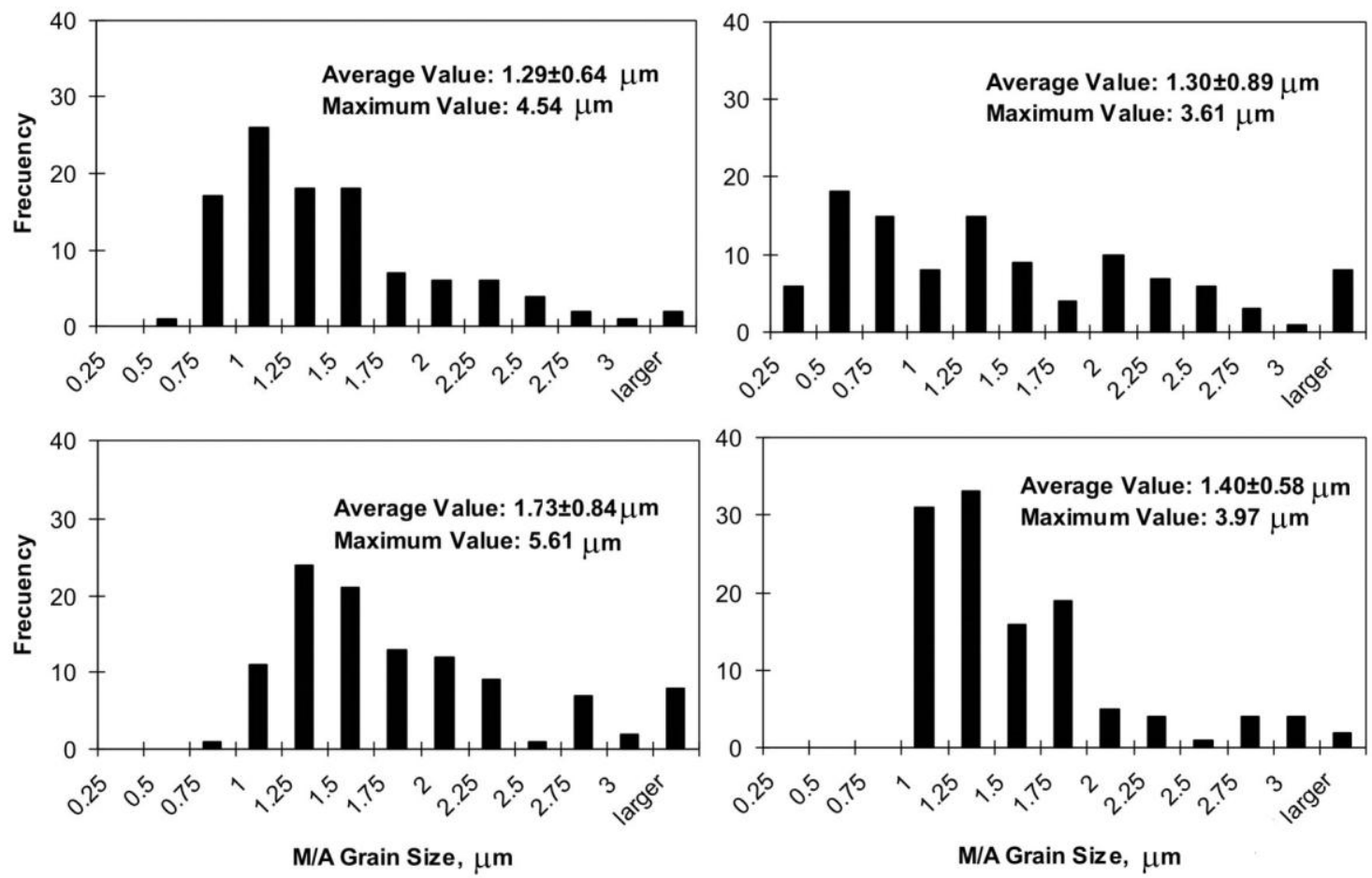

Figure 3.- Size distribution of the equiaxed M/A grains present in granular bainite of the continuously cooled bainitic samples: (a) Steel 1-2; (b) Steel 2-3; (c) Steel 2-1.5; and (d) Steel 2-1200-9. 

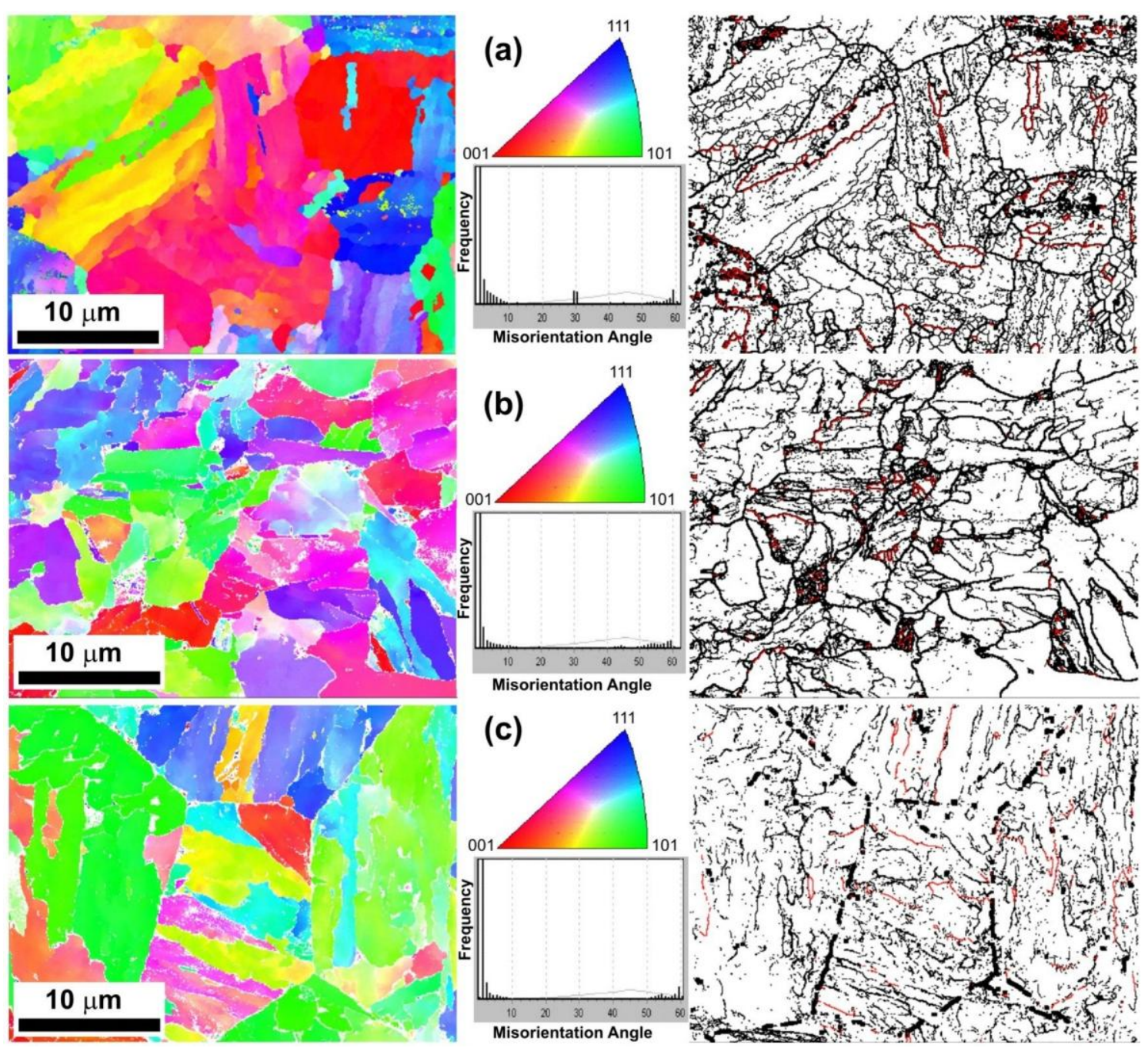

Figure 4.- Orientation imaging map, misorientation map (tolerance angle of $15 \mathrm{deg}$ ) and corresponding misorientation frequency graph of (a) lath-like upper bainite in Steel 1-9 sample and granular bainite in: (b) Steel 2-3 sample and (c) Steel 2-1.5 sample. 

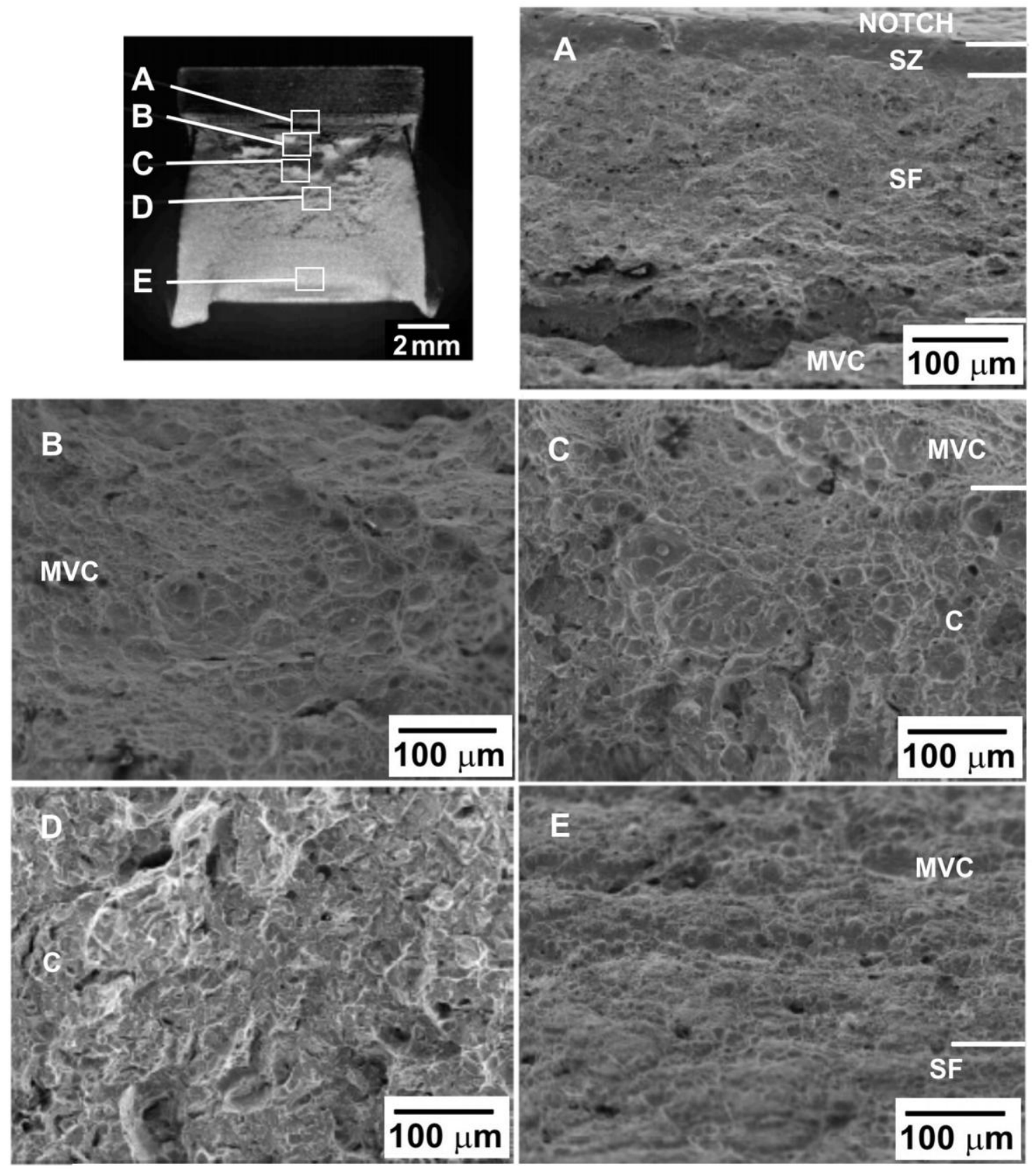

Figure 5.- Fractographs of Steel 1-2.5 impact specimen at room temperature. SZ is stretched zone; SF is shear fracture, MVC is microvoid coalescence; $\mathrm{C}$ is cleavage. 


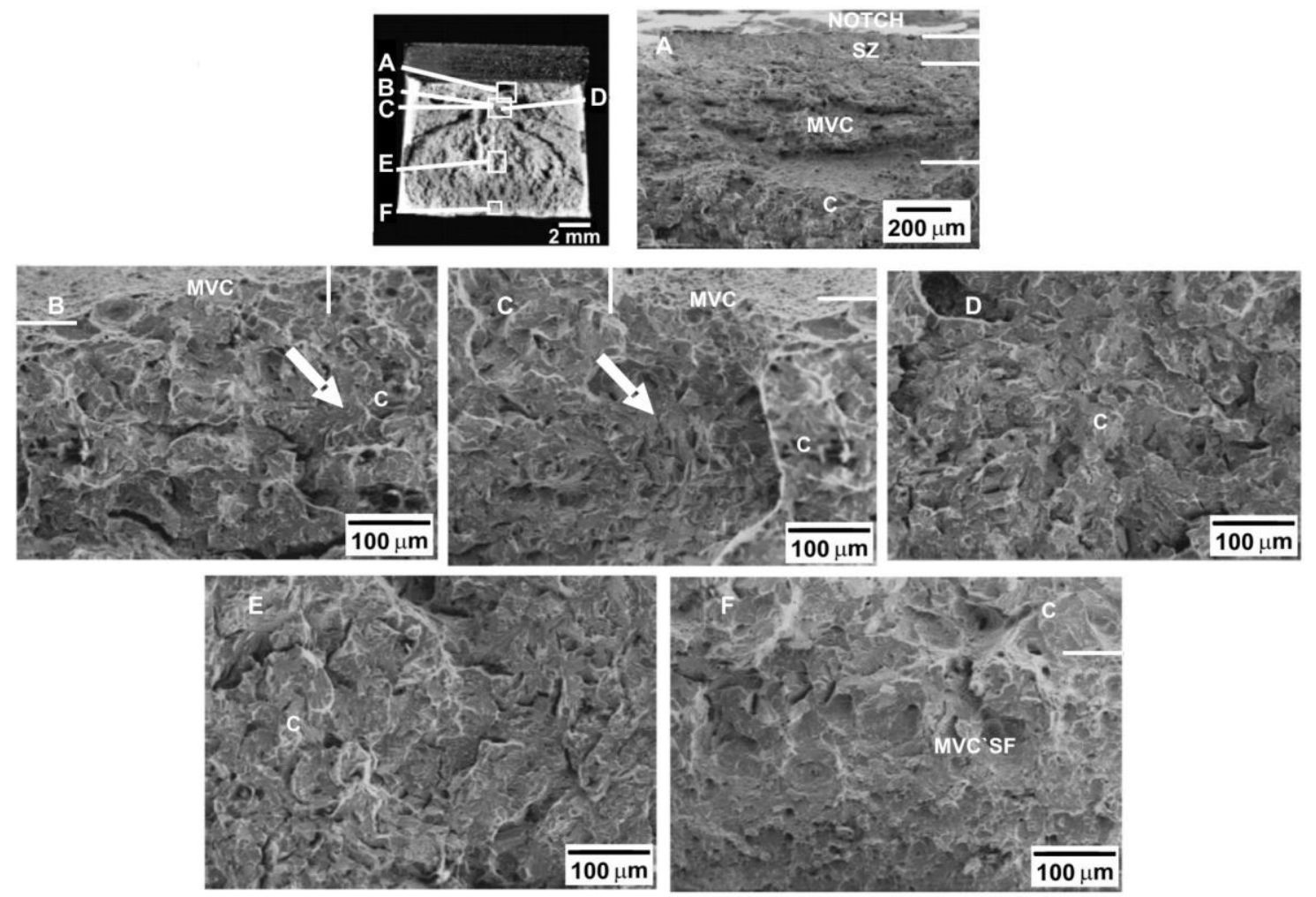

Figure 6.- Fractographs of Steel 1-2 impact specimen at room temperature. SZ is stretched zone; SF is shear fracture, MVC is microvoid coalescence; $\mathrm{C}$ is cleavage. Arrows identify fracture initiation site. 